\title{
Adaptation of the Trust in the Coach Scale into Turkish: Validity and Reliability Study
}

\section{Zafer Doğru*}

Department of Physical Education and Sports, Faculty of Sports Sciences, Hitit University, Corum, Turkey

Study Area: Corum, Turkey

Coordinates: $40^{\circ} 33^{\prime} \mathrm{Oo} " \mathrm{~N} 34^{\circ} 57^{\prime} 14^{\prime \prime} \mathrm{E}$

Key words: Integrity, Benevolence, Competence, Cooperation, ScaleAdaptation

Permission was obtained from the authors of the original scale via e-mail for the adaptation study into Turkish. In addition, ethics committee approval (2019-112) was obtained from the Hitit University Non-Interventional Researches Ethics Committee and the institutional permission was granted by the HUFSS.

\section{Introduction:}

Sports and athletes are generally at the center of attention in the society. Especially in popular sports, this interest is experienced more intensely. The actors of this interest are athletes, coaches, club managers and spectators, in addition to these, the other factors are press and TV. The performance that the athletes perform or will perform is a social phenomenon followed by other interested parties (fans, press, food and beverage vendors, advertisers, etc.). The intense interest and expectation have led to the investigation of the relationships of the athletes with their coaches and to work on this subject. Recent studies have focused on the leadership characteristics of the coaches (Filiz \& Demirhan, 2017; Altı ntaş et al., 2012), factors that affect the behavior of the coaches, situational and demographic characteristics, consequences of the leaders' actions, how the leaders' behavior affects the performance of their athletes and satisfaction of athletes (Filiz \& Demirhan, 2017).

As per Vieira \& Palmer (2012), Gyllensten \& Palmer (2007), and O'Broin \& Palmer (2010), demonstrated in their studies that 'trust' in the coach-athlete relationship is an important dimension in the coaching process. They developed the Coaching Skills Self-Efficacy Scale (CSSES) scale to measure this. They carried out important studies on the leadership characteristics of the coaches with their work titled "Preferred leadership in sports" (Chelladurai \& Saleh, 1978) and "Dimensions of leader behavior in sports:

\section{Abstract}

In this study, the trust in the coach scale has been translated and adpot into Turkish and determined the validity and reliability of the scale. The study group consisted of 340 (232 males and 108 females) competitive sport clubs athlete attended. Cronbach Alpha value of the adapted scale was found to be 0.97 . The internal consistency coefficients of the sub dimensions ranged between o.84-0.95, respectively. Confirmatory factor analysis was performed to test the factor structure obtained after exploratory factor analysis in order to reveal the factor structure of trust in the coach. As a result of confirmatory factor analysis, it was found that the scale has eight-dimensional structure in its adapted form as it is in its original form. As a result, it can be told that the scale adapted into Turkish found to be valid and reliable to measure the attitudes of Turkish Athletes.

development of a leadership scale" (Chelladurai \& Saleh, 1980). Zhang \& Chelladurai (2013) formed the theoretical infrastructure and model of the "trust in the coaches scale" in their extensive study. It is aimed to adapt the 8dimensional "Trust in the Coach Scale" created as a result of the study to the Turkish language. As stated by Zhang \& Chelladurai (2013), statistical evidences did not support the 6th and 8th hypotheses but confirmed the other hypotheses. However, it was thought that this model and scale would be a new and important scale in explaining and discussing the relations of Turkish athletes with their trainers.

Their model (Fig.-1) includes coach characteristics of justice, benevolence, integrity, and competence which are said to contribute to trust in the coach. Trust in the coach, in turn, fosters commitment to leader and willingness to cooperate both of which influence perceived performance. Finally, "trust in the coach" have a direct effect also on perceived performance.

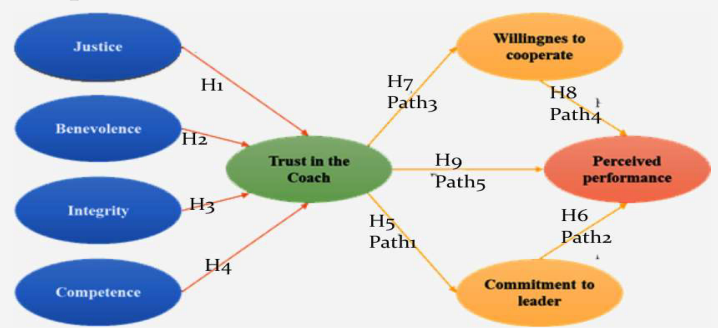

Figure-1: Theoretical model of antecedents and consequences of trust in the coach. $\mathrm{H}=$ hypothesis.

*Author: zaferdogru@gmail.com 


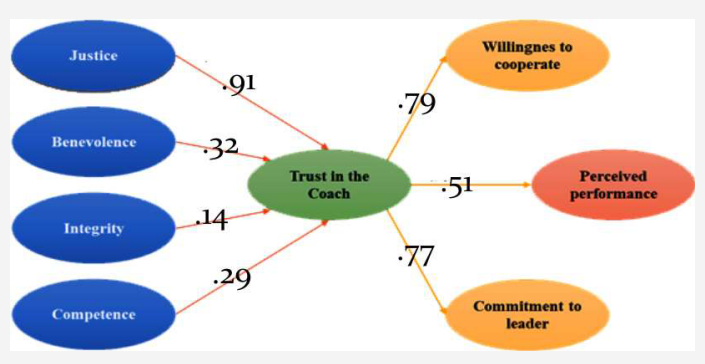

Figure-2: Coefficients for the direct effects model.

The structural model related to the scale revealed at the end of the study is in Fig.-2 (Zhang \& Chelladurai, 2013).

\section{Methodology:}

This paper is a scaleadaptation study.

The athletes who were studying at the Hitit University Faculty of Sports Sciences (HUFSS) were the subjects during the study period and they had already worked one year or more with their coaches.The sample of the study consisted of 340 athletes, the average age was $21.24 \pm 2.150, n=108,31.8 \%$ femaleand $n=232,68.2 \%$ maleathletes.

It was previously recommended that 5 to 10 observations per item would be enough for the exploratory factor analysis in the scale studies (Büyüköztürk, 2002; Doğan \& Başokçu, 2010; Yaşlığlu, 2017). It was also stated that as the sample size increased, sensitivity increased in determining the difference between the obtained data (Hair et al., 1998). There were approximately 14 observations per item for this study.

Athletes studying at the Faculty of Sport Sciences of Hitit University, who were willing to participate in the study and accepted to sign the consent form, were included in the study. The original scale was translated into Turkish and used as a data collection tool. 400 data forms were checked, and 35 missing forms and 25 outlierswere excluded.

In order to adapt the scale, which was published in English, it was translated independently by three expert lecturers in Turkish and English and three English teachers. These translations were brought together by the researcher, experts were asked for their opinions again to decide on the most appropriate meaning, and a single Turkish form was created with the most understandable items that were agreed upon in line with the opinions. Afterwards, the measurement tool was translated back into English by a faculty member who was proficient in English. The conformity of the meanings between the English translation of the scale and its Turkish translation was tried to be accomplished. Validity and reliability studies of the Turkish form were also conducted. Content validity was carried out with three academicians who were experts in the field of coaching education.

Reliability analysis, explanatory and confirmatory factor analyzes were performed. Corrected total item correlations were calculated for items suitability. The factor structure that emerged in the original scale was tested first by exploratory factor analysis (EFA) and then by confirmatory factor analysis (CFA).

A scale can be directly started with confirmatory factor analysis (CFA) for the factor pattern in the culture to be adapted in scale adaptation. Because the factor pattern of the measuring tool in the original culture has been revealed by qualitative and quantitative studies, there are experimental evidences regarding the construct validity of the measuring tool. There are different approaches about how EFA and CFA should be used in scale development and adaptation studies.

While Jöreskog \& Sörbom (1993) recommended doing EFA first, then CFA, Gorsuch stated that CFA was a very powerful test that allowed the assumptions to be tested, and Gerbing \& Hamilton stated that CFA could contribute to EFA by doing it first (cited in Çokluk et al., 2018:283).

Whether the factor design of the measurement tool is preserved in the target culture can be questioned by testing with confirmatory factor analysis (Çokluk et al., 2018: 283). For this reason, exploratory factor analysis (EFA) and confirmatory factor analysis (CFA) were performed to test the 8-factor structure of the scale. Reliability analysis and exploratory factor analysis of the scale were performed by using SPSS 22.0 and confirmatory factor analysis by using LISREL 8.71. Shapiro-Wilk test was used to test the normal distribution, Mann-Whitney $U$ was used to test the difference between the upper and lower $27 \%$ groups.

\section{Results:}

Results of the study were given in this section for the study group; descriptive statistics, reliability analysis, exploratory factor analysis and confirmatory factor analysis. The study group consisted of total 340 athletes, $n=10831.8 \%$ female and $n=23268.2 \%$ male. It was tested whether the data were suitable for normal distribution. It was seen that the data do not show a normal distribution (Common $\mathrm{df}=340$ and p<o.oo1; Table-1).

Table-1: Tests of Normality (Common df=340 and $\mathrm{p}<0.001$ )

\begin{tabular}{llllllll} 
Items & S-Wilk & Items & S-Wilk & Items & S-Wilk & Items & S-Wilk \\
\hline o1 & .783 & 02 & .791 & 03 & .763 & 04 & .751 \\
05 & .782 & 06 & .788 & 07 & .855 & 08 & .775 \\
o9 & .761 & 10 & .822 & 11 & .781 & 12 & .816 \\
13 & .820 & 14 & .791 & 15 & .770 & 16 & .796 \\
17 & .818 & 18 & .840 & 19 & .858 & 20 & .762 \\
21 & .685 & 22 & .800 & 23 & .838 & 24 & .782 \\
\hline
\end{tabular}

After the validity studies, reliability analysis, exploratory and confirmatory factor analyzes were performed and the suitability of the scale for Turkish culture was discussed in this section. For this purpose, reliability analysis was conducted first. The results were presented in Table 3 .

The total Cronbach Alpha value of the 24 items was $\alpha=.97$. This value showed that the items of the scale were highly reliable. .

Tablo-2:Reliability Statistics

\begin{tabular}{cll}
\hline Item & $\begin{array}{l}\text { Original } \\
\text { Scale } \alpha\end{array}$ & $\begin{array}{l}\text { Adapted Scale } \\
\text { Test } \alpha\end{array}$ \\
\hline
\end{tabular}

\begin{tabular}{llll}
\hline Trust & $\mathbf{2}$ & .74 & .84 \\
Justice & 3 & .90 & .89 \\
Benevolence & 3 & .86 & .91 \\
Integrity & 4 & .91 & .93 \\
Competence & 5 & .93 & .95 \\
Commitment & 2 & .76 & .88 \\
Cooperate & 2 & .77 & .89 \\
Performance & 3 & .86 & .89 \\
Total & 24 & - & .97 \\
\hline
\end{tabular}


TECHNOSCIENCE ARTICLE

Explatory Factor Analysis was applied to know whether the items were suitable for factor analysis. Using Bartlett's test of sphericity, the similarity of the correlation matrix was tested. As a result of the test performed in the data group, this hypothesis of similarity was rejected at the level of $\mathrm{p}<$.oo1. This result showed the suitability of the data for factor analysis by revealing the existence of a relationship between the items (Table-4).

Table-3: KMO and Bartlett's test

\begin{tabular}{cccl}
\hline Kaiser-Meyer-Olkin Measure of Sampling Adequacy. & .967 \\
Bartlett's Test of Sphericity & Approx. Chi-Square & 8453.235 \\
df & 276 & Sig. & $.000^{*}$
\end{tabular}

Table-3: showed the suitability of the data for factor analysis.

Table-4: Total variance explained

\begin{tabular}{llll}
\hline Component & Total & \% of Variance & Cumulative \% \\
\hline 1 & 15.229 & 63.452 & 63.452 \\
2 & 1.430 & 5.958 & 69.410 \\
3 & 1.211 & 5.046 & 74.456 \\
4 & .730 & 3.042 & 77.498 \\
5 & .627 & 2.611 & 80.109 \\
6 & .480 & 2.002 & 82.111 \\
7 & .459 & 1.911 & 84.022 \\
8 & .397 & 1.654 & 85.677 \\
\hline
\end{tabular}

As a result of the factor analysis, an 8-dimensional structure emerged in accordance with the original scale. Item extraction was not done. The explained total variance was presented in Table 5. It the resulting eight factors explained $85.677 \%$ of the total variance. The internal consistency coefficients of the sub-dimensions vary between .84 and .95 . After the exploratory factor analysis, confirmatory factor analysis was performed to test the structural compatibility of the items in the scale.

Table-5: Identification of the sub-dimensions of the scale and reliability coefficients

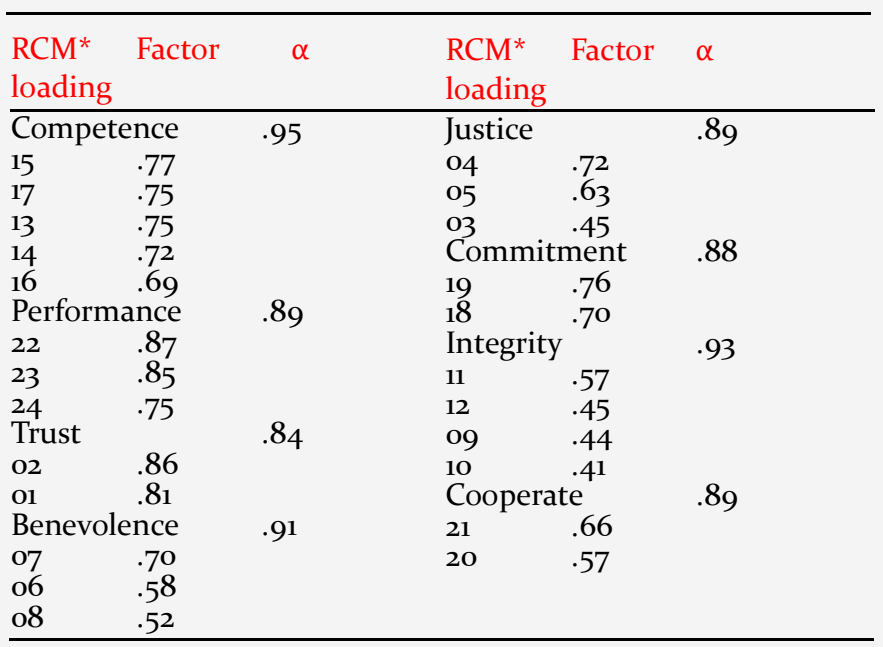

RMC*-Rotated Component Matrixa

Extraction Method: Principal Component Analysis. Rotation Method: Varimax with Kaiser Normalization.

$\alpha$. Rotation converged in 7 iterations.
Ambient Science, 2020: Vol. 07(Sp1); 227-231 DOI:10.21276/ambi.2020.07.sp1.ta12

The values obtained as a result of the Confirmatory Factor Analysis (CFA) were compared with the values in the literature and were presented in Table-6 (SchermellehEngel, Moosbrugger, \& Müller, 2003). The values obtained as a result of the confirmatory factor analysis showed that the model created had an acceptable fit. These values and indicators showed that the scale could be used with 24 items and eight dimensions (Table-6).

Table-6: Goodness of fit Indices Achieved in the CFA

\begin{tabular}{llll}
\hline Fit Measures & Perfect Fit & Acceptable Fit & Achieved Fit \\
\hline X2/sd & $0 \leq \mathrm{X}_{\mathbf{2}} / \mathrm{sd}<\mathbf{2}$ & $\mathbf{2}<\mathrm{X} \mathbf{2} / \mathrm{sd}<3$ & $\mathbf{2 . 3 9}$ \\
RMSEA & $\mathbf{0}<\mathrm{RMSEA}<.05$ & $.05<\mathrm{RMSEA} \leq .08$ & .064 \\
NFI & $.95 \leq \mathrm{NFI} \leq_{\mathbf{1}}$ & $.90 \leq \mathrm{NFI}<.95$ & .98 \\
NNFI & $.97 \leq \mathrm{NNFI} \leq_{\mathbf{1}}$ & $.95 \leq \mathrm{NNFI}<.97$ & .99 \\
CFI & $.97 \leq \mathrm{CFI} \leq_{\mathbf{1}}$ & $.95 \leq \mathrm{CFI}<.97$ & .99 \\
S-RMR & $0 \mathbf{\mathrm { O }} \leq \mathrm{RMR} \leq .05$ & $.05<\mathrm{S}-\mathrm{RMR} \leq .10$ & .036 \\
GFI & $.95 \leq \mathrm{GFI} \leq_{\mathbf{1}}$ & $.90 \leq \mathrm{GFI}<.95$ & .88 \\
AGFI & $.90 \leq \mathrm{AGFI} \leq_{\mathbf{1}}$ & $.85 \leq \mathrm{AGFI} \leq .90$ & .84
\end{tabular}

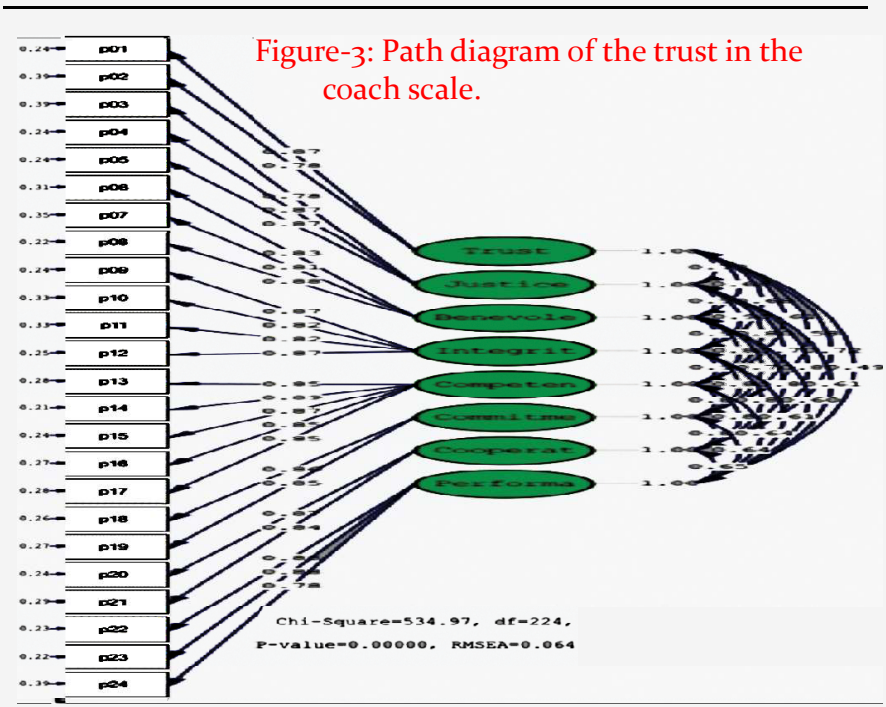

There are different goodness of fit indices used in the assessment of model fit and there are statistical functions that these indexes have. Among the recommended indexes, the most used ones are; the similarity ratio, the chi-square statistic (X2), RMSEA (Root-mean-square error approximation), GFI (Goodness-of-fit index) and AGFI (Adjusted Goodness-of-fit index) (Joreskog \& Sörbom, 2001).

The $\mathrm{X}_{2}$ value is related to the difference between the observed and expected values in covariance matrices. When the sample size of the model fit increases (usually over 200) or the sample size decreases (generally below 10o), the value of the $\mathrm{X}_{2}$ statistic tends to go beyond the fit limits. Therefore, the $\mathrm{X}_{2}$ statistic is affected by the sample size. The $\mathrm{X}_{2}$ statistic is also affected by the multivariate normality assumption (Schumacher \& Lomax, 2004).

RMSEA value equal to or less than .05 is a good fit, between .05 and .08 is sufficient fit, if it is between .08 and 1 is an acceptable fit, if it is greater than 1 is an unacceptable fit (Kaplan, 200o; Schermelleh-Engel, 2003). In another study, 
it was stated that RMSEA value equal or less than .05 corresponds to a perfect fit, values between .08 and .10 correspond to an acceptable fit, and a value greater than .10 to bad fit (Hayduk, 1987).

GFI, which is an indicator of the relative variance and covariance amount, takes a value between "o" and "1" and the proximity of this value to 1 indicates that the fit of the model is better (Hair et al., 1998). The road diagram obtained as a result of the confirmatory factor analysis made to be evaluated within the scope of the literature information is presented in Fig.-3.

\section{Table-7: Correlations}

\begin{tabular}{|c|c|c|c|c|c|c|c|c|}
\hline \multicolumn{9}{|c|}{ Spearman's rho } \\
\hline & $\mathrm{a}$ & $\mathrm{b}$ & c & d & e & $\mathrm{f}$ & g & $\mathrm{h}$ \\
\hline $\bar{a}$ & 1.000 & & & & & & & \\
\hline $\mathrm{b}$ & $.584^{* *}$ & 1.000 & & & & & & \\
\hline c & $.525^{* *}$ & $.749^{* *}$ & 1.000 & & & & & \\
\hline d & $.542^{* *}$ & $.757^{* *}$ & $.792^{* *}$ & 1.000 & & & & \\
\hline e & $.473^{* *}$ & $.707^{* *}$ & $.707^{* *}$ & $.805^{* *}$ & 1.000 & & & \\
\hline $\mathrm{f}$ & $.460^{* *}$ & $.603^{* *}$ & $.628^{* *}$ & $.711^{* *}$ & $.710^{* *}$ & 1.000 & & \\
\hline g & $.560^{* *}$ & $.709^{* *}$ & $.658^{* *}$ & $.716^{* *}$ & $.700^{* *}$ & $.663^{* x}$ & 1.000 & \\
\hline $\mathrm{h}$ & $.422^{* *}$ & $.541^{* *}$ & $.486^{* *}$ & $.522^{* *}$ & $.568^{* *}$ & $.559^{* *}$ & $.557^{* *}$ & 1.000 \\
\hline Mean & 5.89 & 5.97 & 5.82 & 5.86 & 5.83 & $5 \cdot 38$ & $5 \cdot 98$ & 5.49 \\
\hline SD & 1.247 & 1.208 & 1.235 & 1.226 & 1.261 & 1.496 & 1.341 & 1.569 \\
\hline
\end{tabular}

a-Trust; b-Justice; c-Benevolence; d-Integrity;e-Competence;

f-Commitment;g-Cooperate; h-Performance

$\mathrm{n}=340 .{ }^{* *}$ Correlation is significant at the .o1 level (2-tailed).

In the correlation coefficient values of the subdimensions, positive and statistically significant relationships between $.422 \& .805$ were obtained (Table- 8 ).

According to the Lower-Upper group method, item difficulty and item discrimination power values were calculated (Brennan, 1972). Finally, 27\% of the upper group and $27 \%$ of the subgroup were compared for each item to test the discriminative power of the items (Table-8).

Table- 8 revealed that each item had a discriminative power between the athletes in the $27 \%$ uppergroup and $27 \%$ lower group. There were statistically significant differences between the scores of the athletes in the lower and upper groups of $27 \%$ in all 24 expressions, and the scores of the uppergroup were found to be higher.

The scale is 7-point Likert type and consists of eight sub-dimensions, there is no negative expression in the scale. The sub-dimensions of the scale are;

Trust; 1,2

Benevolence; $6,7,8$

Justice; $3,4,5$

Competence; 13, 14, 15, 16, 17

Cooperate; 20,21

Integrity; 9, 10, 11, 12

Commitment; 18,19

Performance; 22, 23, 24.

The original version of the 24 -item scale adapted to the Turkish language and culture is presented in Table 10. The Turkish form is included in the appendices. It is seen that the Turkish form also preserves the stable structure in the original scale.
Table-8: Comparison of 27\% lower-upper groups with MannWhitney U

\begin{tabular}{|c|c|c|c|c|c|c|}
\hline \# & $\begin{array}{l}\text { Groups } \\
\text { of } 27 \%\end{array}$ & $\begin{array}{l}\text { Mean } \\
\text { Rank }\end{array}$ & $\begin{array}{l}\text { Sum of } \\
\text { Rank }\end{array}$ & $\mathrm{U}$ & Z & $\mathrm{p}$ \\
\hline \multirow[t]{2}{*}{01} & Upper & 126.587 & 11646 & 1096 & -9.28631 & $.000^{*}$ \\
\hline & Lower & 58.41304 & 5374 & & & \\
\hline \multirow[t]{2}{*}{02} & Upper & 123.5598 & $11367 \cdot 5$ & 1374.5 & -8.40241 & .000 \\
\hline & Lower & 61.44022 & 5652.5 & & & \\
\hline \multirow[t]{2}{*}{03} & Upper & 133.4076 & 12273.5 & 468.5 & -11.1776 & .000 \\
\hline & Lower & 51.59239 & 4746.5 & & & \\
\hline \multirow[t]{2}{*}{04} & Upper & 133.4293 & $12275 \cdot 5$ & 466.5 & -11.3099 & .000 \\
\hline & Lower & 51.57065 & 4744.5 & & & \\
\hline \multirow[t]{2}{*}{05} & Upper & 134.1522 & 12342 & 400 & -11.3724 & .000 \\
\hline & Lower & 50.84783 & 4678 & & & \\
\hline \multirow[t]{2}{*}{06} & Upper & 132.75 & 12213 & 529 & -10.7639 & .000 \\
\hline & Lower & 52.25 & 4807 & & & \\
\hline \multirow[t]{2}{*}{07} & Upper & 133.2283 & 12257 & 485 & -10.7269 & .000 \\
\hline & Lower & 51.77174 & 4763 & & & \\
\hline \multirow[t]{2}{*}{ o8 } & Upper & $135 \cdot 3913$ & 12456 & 286 & -11.5445 & .000 \\
\hline & Lower & 49.6087 & 4564 & & & \\
\hline \multirow[t]{2}{*}{09} & Upper & 135.5652 & 12472 & 270 & -11.5984 & .000 \\
\hline & Lower & $49 \cdot 43478$ & 4548 & & & \\
\hline \multirow[t]{2}{*}{10} & Upper & 137.212 & 12623.5 & 118.5 & -11.936 & .000 \\
\hline & Lower & $47 \cdot 78804$ & 4396.5 & & & \\
\hline \multirow[t]{2}{*}{11} & Upper & 132.2935 & 12171 & 571 & -10.7969 & .000 \\
\hline & Lower & $52.7065^{2}$ & 4849 & & & \\
\hline \multirow[t]{2}{*}{12} & Upper & 135.5978 & 12475 & 267 & -11.5763 & .000 \\
\hline & Lower & 49.40217 & 4545 & & & \\
\hline \multirow[t]{2}{*}{13} & Upper & 135.087 & 12428 & 314 & -11.3778 & .000 \\
\hline & Lower & 49.91304 & 4592 & & & \\
\hline \multirow[t]{2}{*}{14} & Upper & 135.1196 & 12431 & 311 & -11.438 & .000 \\
\hline & Lower & 49.88043 & 4589 & & & \\
\hline \multirow[t]{2}{*}{15} & Upper & 134.9674 & 12417 & 325 & -11.4277 & .000 \\
\hline & Lower & 50.03261 & 4603 & & & \\
\hline \multirow[t]{2}{*}{16} & Upper & 133.4891 & 12281 & 461 & -11.0914 & .000 \\
\hline & Lower & 51.51087 & 4739 & & & \\
\hline \multirow[t]{2}{*}{17} & Upper & 136.9348 & 12598 & 144 & -11.8643 & .000 \\
\hline & Lower & 48.06522 & 4422 & & & \\
\hline \multirow[t]{2}{*}{18} & Upper & 133.8043 & 12310 & 432 & -10.8602 & .000 \\
\hline & Lower & 51.19565 & 4710 & & & \\
\hline \multirow[t]{2}{*}{19} & Upper & 133 & 12236 & 506 & -10.6404 & .000 \\
\hline & Lower & $5^{2}$ & 4784 & & & \\
\hline \multirow[t]{2}{*}{20} & Upper & 132.9674 & 12233 & 509 & -10.9868 & .000 \\
\hline & Lower & 52.03261 & 4787 & & & \\
\hline \multirow[t]{2}{*}{21} & Upper & 131.3043 & 12080 & 662 & -10.8614 & .000 \\
\hline & Lower & 53.69565 & 4940 & & & \\
\hline 22 & Upper & 131.2772 & 12077.5 & 664.5 & -10.3889 & .000 \\
\hline & Lower & 53.72283 & 4942.5 & & & \\
\hline 23 & Upper & 132.3315 & $12174 \cdot 5$ & 567.5 & -10.4907 & .000 \\
\hline & Lower & 52.66848 & $4845 \cdot 5$ & & & \\
\hline 24 & Upper & 130.8696 & 12040 & 702 & -10.3135 & .000 \\
\hline & Lower & 54.13043 & 4980 & & & $\mathrm{p}<.001$ \\
\hline
\end{tabular}

Discussion:

So far, many studies have generally tried to measure and evaluate the relationships between coaches and athletes by using developed and/or adapted scales. During the period of the current study, no scale with a structural model was found in the available resources. It was thought that this 
TECHNOSCIENCE ARTICLE

adapted scale (field-specific measurement tool) would contribute to the literature. In general, there are constant changes in the training conditions of athletes, many experimental studies are carried out for performance; such as duration, load, intensity, diet, ergogenic aids.

Table-9: Final version of "Trust in the Coach" Scale (TCS)

\begin{tabular}{cccccccc}
\hline & \multicolumn{3}{c}{ Strongly disagree } & & \multicolumn{2}{c}{ Strongly agree } \\
Items & 1 & 2 & 3 & 4 & 5 & 6 & 7 \\
\hline
\end{tabular}

o1- I can freely share my ideas, feelings, and hopes with my coach.

o2- I would be comfortable giving coach a task or problem that was critical to me.

03- My coach appreciates the work done by every athlete.

04- My coach tries to be fair in dealings with athletes.

05- My coach has a strong sense of justice.

6- My coach really looks out for what is important to me.

o7- My needs and desires are very important to my coach.

o8- My coach is willing to go out of the way to help me.

o9- My coach deals honestly with me.

10- My coach always tells me the truth.

11- Sound principles seem to guide my coach's behavior.

12- I like my coach's values.

13- My coach has special abilities that can increase our performance.

14- My coach is very capable of performing the coaching job.

15- My coach is known to be successful at the things he/she tries to do.

16- I feel very confident about my coach's skills.

17- My coach has much knowledge about the work that needs done.

18- Since joining this team, my personal values and those of my coach

have become more similar.

19- I feel a sense of belonging with my coach.

20- I am willing to cooperate with my coach to get the work done.

21- I am willing to communicate with my coach.

22- My team's victories this season.

23- The extent to which the team has met its goals for the season thus far. 24- The improvement in my performance over the previous season

One of the important keys in sportive performance is a coach-athlete relationship and it is known that the quality of this relationship affects the performance of the athletes (Filiz \& Demirhan, 2017; Zhang \& Chelladurai, 2013; Alt.ntaş et al., 2012; Jowett, 2003; Dirks, 2000; Mayer, Davis \& Schoolman, 1995; Chelladurai \& Saleh, 1980; Chelladurai \& Saleh, 1978).

The study was thought to be valuable as the relationship between the coach and athlete, based on the literature review mentioned above. This scale, which deals with the relationships between athletes and coaches on the basis of trust, has been adapted to Turkish culture and language. The results of both EFA and CFA showed that the adapted scale was a valid and reliable scale. A Turkish form was created as Antrenöre Güven Ölçeği (AGÖ). This scale is thought to be very important and useful in terms of measuring the confidencelevels of athletes in their coaches. This scale adaptation study was carried out by occupying athletes from team sports studying at Hitit University Faculty of Sport Sciences, and it is recommended to redo the same study by expanding the sample size by recruiting athletes from individual sports. It was considered that amateur and professional athletes could be used in studies to be conducted within the framework of different variables such as different sports branches, age, gender, sports age and
Ambient Science, 2020: Vol. 07(Sp1); 227-231 DOI:10.21276/ambi.2020.07.sp1.ta12

duration of working with the coach.

It was also thought that the scale could be a pioneer in evaluating the coach-athlete relationships by using it as a measurement tool in the research subjects.

\section{References:}

Altıntaş, A., Çetinkalp, Z., \& Aşçı, F. (2012): Evaluating the CoachAthlete Relationship: Validity and Reliability Study. Hacettepe J. Sport Sci., 23(3):119-128.

Brennan, R.L. (1972): A Generalized upper-lower item discrimination index. Edu. Psychol. Measure., 32(2):289-303.

Büyüköztürk, Ș. (2002): Factor analysis: basic concepts and using to development scale. Edu. Admin. Theory Prac., (Kuram ve Uygulamalarda Eğitim Yönetimi), $32(32): 470-483$.

Chelladurai, P., \& Saleh S.D. (1978): Preferred leadership in sports. Can. J.Appl. Sport Sci., 3:85-92.

Chelladurai, P., \& Saleh, S.D. (1980): Dimensions of leader behavior in sports: development of a leadership scale. L. Sport Psychol., 2(1):34-45.

Çokluk, Ö., Şekercioğlu, G. \& Büyüköztürk, Ş. (2018): Multivariate Statistics for Social Sciences. $5^{\text {th }}$ Edition. (Sosyal Bilimler İçin Çok Değișkenli İstatistik. 5. Baskı.) Pub. by: Pegem Akademi, Ankara, Turkey.

Doğan, N. \& Başokçu, T. (2010): Comparison of the results of factor analysis and graded cluster analysis applied for the statistical attitudescale.J. Measur. Eval. Edu. Psychol., 1(2):65-71.

Filiz, B., \& Demirhan, G. (2017): Adaptation of the Coaching Behavior Assessment Questionnaire Into the Turkish Culture. SPORMETRE J. Phys. Edu. Sport Sci., 15(1):1-10.

Hair, J.F., Anderson, R.E., Tatham, R.L., \& Black, W.C. (1998): Multivariate Data Analysis (5th ed.). Pub. by: Pearson Education, New Jersey.

Hayduk, L.A. (1987): Structural Equation Modelling with lisrel Essential and Advances. Pub. by: The John Hopkins University Press.

Joreskog, K. \& Sörbom, D. (2001): Lisrel 8: User's Reference Guide. Pub. by: Scientific Software International Inc.

Jowett, S. (2003): When the "Honeymoon" Is Over: A Case Study of a Coach-Athlete Dyad in Crisis. Sport Psychol., 17(4):444-46o.

Kaplan, D. (2000): Evaluating and Modifying Structural Equation Models. Structural Equation Modelling: Foundations and Extensions. 1st ed. Pub. by: Sage Publications, Thousand Oaks, CA.

Schermelleh-Engel, K., Moosbrugger, H. \& Müller, H. (2003): Evaluating the fit of structural equation models: tests of significance and descriptive ve goodness of fit measures. Methods Psychol. Res. Online, 8(2):23-74.

Schumacher, R.E., \& Lomax R.G., (2004): A beginner's Guide to Sem, 2nd ed, Pub. by: Lawrence Erlbaum Associotes, publishers, New Jersey.

Vieira, D.A., \& Palmer, S. (2012): The coaching skills self-efficacy scale (CSSES): Avalidation studyamong a Portuguese sample. Coach. Psychol., 8(1):6-11.

Yaşlığlu, M.M. (2017): Factor analysis and validity in social sciences: application of exploratory and Confirmatory Factor Analyses. Istanbul Univers. J. School Busi. 46:74-85.

Zhang, Z., \& Chelladurai, P. (2013): Antecedents and consequences of athlete's trust in the coach. J. Sport Health Sci., 2:115-121. 